\title{
CONTRATO, VISADA E ETHOS NO TAPETE VERMELHO DA 75ª EDIÇÃO DO GLOBO DE OURO
}

\author{
KELLY F. MAYRINK DRUMOND ${ }^{1}$
}

Programa de Pós-Graduação em Estudos de Linguagens - POSLING Centro Federal de Educação Tecnológica de Minas Gerais (CEFET-MG) Av. Amazonas, 5253 - Nova Suíça, Belo Horizonte - MG -Brasil

\section{kellymayrinkbhegmail.com}

\begin{abstract}
Resumo. Em sua $75^{a}$ edição, o Globo de Ouro foi marcado por um protesto convocado pelo movimento Time's up, que levou as celebridades a estrelarem o tapete vermelho com uma mesma cor de roupa: o preto. Com base nesse corpus e partindo dos dispositivos teóricos da Análise do Discurso, o presente artigo refletirá sobre a existência de uma prática discursiva não verbal intrínseca às roupas, transformadas em instrumento político. Nesse ato linguareiro, identificar-se-ão os conceitos de "Contrato de Comunicação", "Visadas discursivas" e "Ethos", considerando análises feitas a partir, principalmente, dos postulados de Charaudeau (2004) $e$ Maingueneau (2005).
\end{abstract}

Palavras-chave: Análise do Discurso; Contrato; Visada; Ethos; Globo de Ouro.

\begin{abstract}
In its 75th edition, the Golden Globe brought attention to a protest convened by a movement called Time's up, which culminated with the hottest celebrities choosing to wear all black on the red carpet. Based on this corpus and using the theoretical aspects of the Discourse Analysis, the present paper will discuss the existence of a non-verbal discursive practice intrinsic to the clothes, which is transformed in a political instrument. In this linguistic act, the concepts of "Communication Contract", "Visées" and "Ethos" will be identified considering the analyses carried out, principally, in the Charaudeau's and Maingueneau's postulates.
\end{abstract}

Keywords: Discourse analysis; Contract of communication; Visées; Ethos; Golden Globe.

\section{INTRODUÇÃO}

A escolha ${ }^{2}$ de determinada roupa é um ato complexo, repleto de significações e cargas ideológicas, como uma espécie de código. "Diga-me o que vestes e eu te direi

\footnotetext{
${ }^{1}$ Mestra do Programa Estudos de Linguagens do Centro Federal de Educação Tecnológica de Minas Gerais (CEFET-MG).

2 Para a compreensão da prática discursiva não verbal intrínseca às roupas proposta neste artigo, consideramos que o âmbito de escolha aqui referido é o consciente, quando há um pensamento e/ou
} 
como estás, quanto tens, a que grupo pertences", é a frase usada por Coelho (1995) que ilustra a carga de informações existentes nas roupas. Para o filósofo francês Gilles Lipovetsky, em sua obra $O$ império do efêmero: a moda e seu destino nas sociedades modernas (2001), "a moda tem ligação com o prazer de ver, mas também com o prazer de ser visto, de exibir-se ao olhar do outro". O autor associa a moda a um aparelho gerador de juízo estético e social.

Manifesta-se pela escolha das roupas a tendência para pertencer ou, alternativamente, a tendência de querer ser considerado como pertencente, com relação a uma determinada categoria ou tipologia social. Desta maneira, certas vestimentas são suficientes para a determinação da profissão ou do poderio financeiro de um indivíduo na sociedade, conforme citação a seguir de DORFLES (1979):

A moda torna-se uma importante e cômoda maneira de sinalética e mesmo de promoção social; por vezes uma maneira tão eficaz que vale mais que qualquer diploma, láurea ou título de estudo para sancionar a pertença de um indivíduo a uma determinada categoria profissional. É o que se vê hoje quando a bata de um médico, a toga de um advogado, o cabeção de um religioso são suficientes para declarar a pertença de um indivíduo a uma destas categorias sociais ou profissionais (DORFLES, 1979, p. 97).

As roupas estabelecem castas, determinam degraus na escada social. Existe uma associação entre a identidade da pessoa e o que ela veste. Desde os tempos primitivos, o uso da pele de um animal mais difícil de caçar era um fator de prestígio. Diz-se que mesmo calado o sujeito se mostra, mostra a sua imagem.

Para Umberto Eco (1982, p.17), temos que "a linguagem do vestuário, tal como a linguagem verbal, não serve apenas para transmitir certos significados, mediante certas formas significativas. Serve também para identificar posições ideológicas, segundo os significados transmitidos e as formas significativas que foram escolhidas para transmitir". E essa construção se dá por símbolos, cores, texturas, volumes e proporções que, organizados na forma de um vestuário, formam um discurso narrativo.

No suporte do corpo do usuário, a vestimenta aparece como uma das principais formas de discurso da identidade, no sentido de que aquilo que é usado tende a externalizar o que é intrínseco ao sujeito. É o que Charaudeau e Maingueneau (2004a, p. 433) explicam ao afirmarem que "discursos sociais se configuram ora de maneira explícita, 'objetivando-se' em signos emblemáticos, ora de uma maneira implícita, por alusão".

Tal noção se torna fundamental para a análise dos acontecimentos ocorridos durante a $75^{\mathrm{a}}$ edição da premiação Globo de Ouro, quando as famosas atrizes se apropriaram das roupas como instrumento de protesto, e escolheram uma única cor para legitimar um discurso social e passar a mensagem de união em prol da causa contra abusos e desigualdade de gênero.

elaboração sobre o traje. Algumas teorias da moda consideram a existência de um âmbito inconsciente, quando não há uma avaliação sobre o possível impacto que a escolha indumentária poderá causar, opção essa vinculada, muitas vezes, ao humor, emoções e/ou sensações do momento. 
Nesse cenário, a cor preta assume uma carga simbólica bastante expressiva. Percebida na cultura ocidental como a cor do luto e da negação, a identificação imediata se dá com o polo negativo. O preto, como não-cor, estará em oposição à presença das cores. É o que afirma Luciano Guimarães (2004), contextualizando que, na política, a cor preta mantém a denotação de protesto. A partir desses códigos socialmente compartilhados, nota-se que a escolha pela padronização de cor no tapete vermelho tem raízes sociais mais profundas.

A partir da repercussão midiática, observa-se a lógica identificatória da moda construída a partir dos discursos firmados pela indumentária. Esse autorretrato discursivo afirmado na moda funciona como um pacto referencialista dos contratos e discursos político-sociais.

A escolha da roupa como um dos referenciadores do protesto do movimento Time's up na $75^{\text {a }}$ edição do Globo do Ouro constitui o corpus deste artigo, cujo objetivo é analisar a existência de uma prática discursiva não verbal intrínseca às roupas e, a partir desta enunciação não verbal, identificar, dentro das vertentes dos estudos em Análise do Discurso (AD), os conceitos de Contrato de Comunicação, Visadas, Ethos e suas derivações.

\section{AS ROUPAS DO RED CARPET}

Os red carpets são caracterizados pelas cerimônias de premiações mundiais que homenageiam profissionais do mundo do cinema, televisão e música, principalmente nos Estados Unidos. Emmy, Grammy, BAFTA, Golden Globe Awards (Globo de Ouro) e Oscar, são algumas das premiações de grande importância para o ramo do entretenimento, e costumam ocorrer uma vez ao ano.

Visando a um ideal de glamour - entendendo o tapete vermelho como uma passarela exclusiva para os honrados e homenageados -, celebridades se apropriam de tecidos, texturas e cores, elementos que, dispostos conforme as orientações e usos de quem os veste, garantem uma imagem estética apropriada à intenção do mensageiro. Partindo dessa decodificação dos signos, Roland Barthes, em sua obra "Sistema da Moda", encontrou no vestuário uma forma de comunicação que, ao ser analisada, adquire um caráter poético:

Pode-se esperar do vestuário que ele constitua um excelente objeto poético; em primeiro lugar, porque mobiliza com muita variedade todas as qualidades da matéria: substância, forma, cor, tactilidade, movimento, porte, luminosidade; em segundo lugar, referindo-se ao corpo e funcionando ao mesmo tempo como substituto e máscara dele, o vestuário certamente é objeto de grande investimento; essa disposição "poética" é comprovada pela frequência e qualidade das descrições indumentárias na literatura (BARTHES, 2009, p.350).

O autor apresenta três tipos de vestuário: o real, o imagético e o escrito e, com base em um amplo estudo, apresenta um método em que a estrutura do vestuário é descrita e analisada a partir da semiologia, reforçando o posicionamento das roupas não apenas como moda, mas também como discurso. "Assim nasce um conjunto de objetos e situações interligados, não mais por uma lógica dos usos ou dos signos, mas por 
injunções de tipo bem diferente, que são as injunções da narrativa." (BARTHES, 2009, p.366)

Sob os holofotes e expectativas do público e da imprensa, o tapete vermelho ${ }^{3}$ se transformou no momento ápice em que a vaidade dos famosos ligados à indústria do entretenimento se mostra mais visível. $\mathrm{O}$ visual dos sonhos exige beleza e autenticidade dos famosos, sob o risco de entrarem para as listas das pessoas mal vestidas.

Dessa forma, constrói-se uma espécie de acordo prévio quanto ao que se esperar dos eventos red carpets, identificando, assim, o postulado de Patrick Charaudeau quanto ao Contrato de Comunicação.

\section{A IDENTIFICAÇÃO DO CONTRATO COMUNICACIONAL E SUA POSSÍVEL RUPTURA}

A regularidade anual, o histórico das edições e o formato categorizam o Globo de Ouro dentro do gênero discursivo do entretenimento e, partindo desta percepção de discurso, é possível colocar em destaque a relação interativa e intencional da premiação com os espectadores. Essa relação é o que Charaudeau (apud ROLIM, 2000) aponta como sendo o contrato comunicacional:

O ritual constituído pelo conjunto das determinações que codificam as práticas sociolinguageiras, ou seja, das circunstâncias do discurso. A noção de contrato pressupõe que os indivíduos presentes em um mesmo corpo de práticas sociais possam se colocar de acordo sobre as representações dessas práticas (ROLIM, 2000, p.29).

Realizado tradicionalmente no Hilton Hotel, em Los Angeles, o Globo de Ouro se apresenta a partir de uma noção prévia de formato: não tão grandioso quanto o Oscar, oferece um jantar para os convidados e indicados em suas respectivas categorias, além de um tapete vermelho com surpreendentes 137 metros de comprimento ${ }^{4}$, por onde passam os indicados aos prêmios, além de outros artistas e convidados.

As representações imaginárias acerca da premiação se associam a dois postulados básicos da teoria Semiolinguística na formulação do quadro enunciativo: o da ritualização das trocas linguageiras - que afirma que o contrato comunicativo é determinado por convenções e regras - e o da intencionalidade - que dispõe que haja um reconhecimento mútuo entre os parceiros do ato de comunicação (ROLIM, 2000).

Nesse cenário, exuberância, estilo e diferenciação fazem do dress code um legitimo ato enunciativo, repleto de significações, reforçando o reconhecimento de uma realidade com a utilização de signos. Essa identificação comunicativa se dá, em parte, pelo repertório cultural do receptor da mensagem, visto que existe uma associação de cores, formas e padrões de roupas com possíveis intenções de uso. Como, por exemplo,

\footnotetext{
${ }^{3}$ Segundo Liberatore (2005), o tapete vermelho tem duas formas de uso mais frequente: como caminho demarcado e como espaço de estar sobre. O cortejo sobre uma passarela vermelha - "espaço sagrado destinado aos que são especialmente destacados" - apresenta-se tanto como espaço de passagem como espaço do acontecimento da ação.

${ }^{4}$ Globo de Ouro. Disponível em: <encurtador.com.br/iLV46 >. Acesso em 15 de agosto de 2020.
} 
a classificação do vestuário em dia a dia, roupas para festas, para passeios, etc.

Tradicionalmente, à época dos eventos de tapetes vermelhos, a expectativa do público é muito grande e todos os olhares se voltam para as ostentações glamourosas de grifes de roupas e acessórios. Apesar das polêmicas sobre negociações milionárias entre estilistas e celebridades, como matéria publicada pelo site Elle ${ }^{5}$, o red carpet funciona sob a ótica da sedução. Em veiculação na Folha de São Paulo ${ }^{6}$, Pedro Diniz cita, entre aspas, a fala do estilista Jonathan Saunder segundo o qual a confiança é o maior desejo das celebridades que buscam "roupas que lisonjeiem seus corpos e as mostrem em sua melhor luz para experimentar padrões que podem não ter considerado usar antes", expectativa essa reafirmada pela fala de Stefano Gabbana, da reconhecida grife Dolce\&Gabbana, que diz que "atrizes do Oscar querem ter algo único, mas impõem regras e se sentem inseguras facilmente".

A $75^{\text {a }}$ cerimônia de entrega do Globo de Ouro foi marcada por uma possível quebra do contrato comunicacional. Porém, apesar da transgressão, a padronização da cor não significa, necessariamente, a ruptura do contrato comunicacional do evento, visto que mantiveram-se as representações supostamente partilhadas acerca da premiação: apesar de possuírem a mesma cor, as variações dos modelos das roupas deram o que falar. Detalhes, brilhos, modelagens e tecidos mantiveram as diferenciações, reforçando o status e o glamour, imprimindo aos estilos discursos passíveis de efetivação. Exemplo disto são as listas de classificação das mais bem vestidas e das mais mal vestidas da noite ${ }^{7}$. Dessa forma, compreende-se que a instância de recepção, entendida pelo viés do contrato de comunicação, continua reconhecendo a exuberância, o estilo e a diferenciação das roupas, mesmo que todas sejam pretas.

Entendendo as dinâmicas do contexto sociocultural desse enunciatário (Globo de Ouro) e seus destinatários (celebridades, espectadores, pessoas ligadas à moda), pode-se identificar a escolha da roupa como um referencial de protesto, não se limitando, este, ao discurso verbal. Essa é uma estratégia discursiva que reforça o importante papel da roupa como parte do discurso social.

Essa intenção comunicativa pode ser classificada a partir do conceito Visada Discursiva que, segundo as discussões do semiolinguista Patrick Charaudeau (2004, 2006), orienta todo o ato de linguagem. E é essa intencionalidade psico-sócio-discursiva que será abordada a seguir.

5 O red carpet é um negócio milionário para stylists e celebridades. Disponível em:<https://elle.abril.com.br/moda/o-red-carpet-e-um-negocio-milionario-para-stylists-e-celebridades/>. Acesso em 15 de maio de 2018.

6 Contratos milionários determinam os vestidos do tapete vermelho. Disponível em:< https://www1.folha.uol.com.br/serafina/2017/12/1937324-contratos-milionarios-determinam-os-vestidosdo-tapete-vermelho.shtml >. Acesso em 15 de agosto de 2020.

${ }^{7}$ Globo de Ouro 2018 | Os mais bem vestidos e os mais mal vestidos da noite. Disponível em:<https://observatoriodocinema.bol.uol.com.br/listas/2018/01/globo-de-ouro-2018-os-mais-bemvestidos-e-os-mais-mal-vestidos-da-noite>. Acesso em 15 de maio de 2019. 


\section{ANÁLISE SOBRE AS VISADAS DISCURSIVAS}

Na Análise do Discurso, o conceito de Visada Discursiva refere-se ao uso de instruções situacionais cujo sujeito falante se orienta a fim de obter a legitimidade ou captar a audiência do sujeito destinatário para além da ancoragem situacional.

Todo sujeito, ao produzir um ato de linguagem, está motivado por uma intenção. A finalidade de influência ou interferência sobre o outro determina a escolha das estratégias discursivas feita pelo sujeito comunicante. Na $75^{\mathrm{a}}$ edição do Globo de Ouro, a estratégia discursiva fundamentou-se na indumentária como forma de expressão. Escolhidas como instrumento político, o movimento Time's up se apropriou das roupas para reforçar o protesto contra os abusos e a desigualdade de gênero. A estratégia do movimento surgiu após a divulgação, pelo The New York Times ${ }^{8}$, de dezenas de denúncias contra o produtor Harvey Weisten, do estúdio Miramax, responsável pelo sucesso de diversas atrizes na década de 90. Depois dele, inúmeros profissionais de diversas áreas do entretenimento foram denunciados, incluindo os atores Kevin Spacey, Dustin Hoffman, Casey Affleck, diretores como Brett Retmer, dentre outros.

Considerando a repercussão mundial da premiação, o movimento Time's up, com o endosso de mulheres como a roteirista Shonda Rhimes e as atrizes Meryl Streep e Reese Witherspoon, convidou as celebridades a usarem looks pretos como forma de protesto, fazendo do dress code um elemento de comprometimento social. De acordo com as Visadas (visées) apresentadas por Charaudeau (2004), identifica-se essa intencionalidade sob as seguintes perspectivas e seus efeitos pretendidos:

- Visada de incitação: segundo o autor (2004, p.23), refere-se ao 'Eu querer "mandar fazer", mas não estar em posição de autoridade. Assim, não pode, senão, incitar a fazer; ele deve, então, "fazer acreditar" (por persuasão ou sedução) ao Tu que ele será o beneficiário de seu próprio ato; o Tu está, dessa forma, em posição de "dever acreditar" que, se ele age, é para o seu próprio bem.

Esta Visada pode ser claramente identificada na postagem no Instagram $^{9}$ do movimento Time's up, veiculada no dia do evento de premiação. O texto que diz "Domingo vestimos preto para manifestar solidariedade às mulheres e homens em todos os lugares que foram silenciados pela discriminação, assédio ou abuso. Aonde quer que você esteja, quem você seja, o que for que esteja fazendo, junte-se a nós", traz os elementos de estímulo, incentivo e incitamento à aderência ao movimento.

\footnotetext{
${ }^{8}$ THE NEW YORK TIMES, Harvey Weinstein Paid Off Sexual Harassment Accusers for Decades. Disponível em:<https://www.nytimes.com/2017/10/05/us/harvey-weinstein-harassmentallegations.html/>. Acesso em 10 de maio de 2020.

${ }^{9}$ Instagram Times' up. Disponível em:<https://www.instagram.com/timesupnow/>. Acesso em 07 de janeiro de 2020 .
} 
Figura 1 - Print de postagem do Instagram do movimento Time's Up



Fonte: Instagram Times' up. Disponível em:<https://www.instagram.com/timesupnow/>. Acesso em 07 de janeiro de 2020.

- Visada de informação: segundo os postulados de Charaudeau (2004, p.23), nesta Visada o Eu quer "fazer saber", e ele está legitimado em sua posição de saber; o Tu se encontra na posição de "dever saber" alguma coisa sobre a existência dos fatos, ou sobre o porquê ou o como de seu surgimento.

Tal conceito fundamenta o discurso de Meryl Streep em entrevista concedida a Ryan Seacrest (informação verbal, 2018) ${ }^{10}$ que, a partir de sua legitimação como indicada ao prêmio de melhor atriz, elucidou:

Eu acho que as pessoas estão conscientes, agora, de um desequilíbrio de poder, e é algo que leva ao abuso. Isso é levado ao abuso em nossa própria indústria, e é levado ao abuso em todo o campo de trabalho dos trabalhadores domésticos. Está nas forças armadas, está no Congresso, está em toda parte. E queremos consertar isso. E nos sentimos meio encorajados neste momento específico para ficarmos juntos em uma linha espessa que se divide a partir de agora.

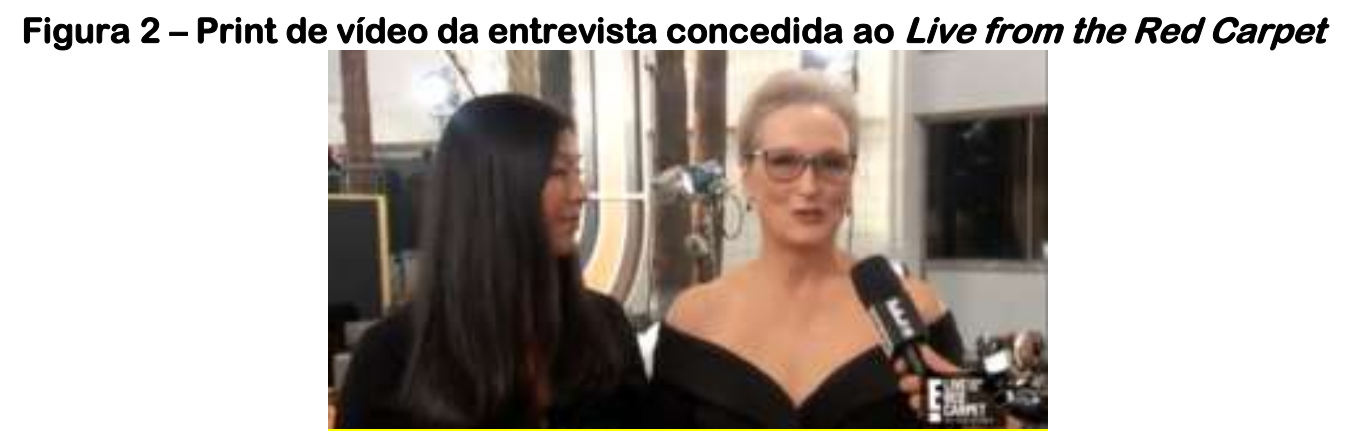

Fonte: E! Entertainment Television. Disponível em:< encurtador.com.br/koBDX>. Acesso em 07 de janeiro de 2020.

- Visada de Captação: o Eu quer "fazer sentir" aciona estratégias capazes de seduzir o espectador através de estados emocionais aptos a movimentar toda uma ação

\footnotetext{
${ }^{10}$ Fala da atriz Meryl Streep. Entrevista concedida a Ryan Seacrest, em transmissão do programa Live from the Red Carpetpor, ocasião de homenagem ao Globo de Ouro 2018. Los Angeles, 7 jan. 2018. Disponível em: <https://www.eonline.com/news/904360/meryl-streep-speaks-out-on-abuse-in-allindustries-on-2018-golden-globes-red-carpet>. Acesso 7 de janeiro de 2020.
} 
dramatizante desse $\mathrm{Tu}$, o que implica na construção de um objetivo comunicativo sedutor (Charaudeau, 2006). Orienta-se em direção ao parceiro da troca, instituído como destinatário de uma mensagem e que necessita ser despertado para o propósito que o eu deseja comunicar.

Esta Visada está na fala de Oprah Winfrey (informação verbal, 2018) ${ }^{11}$, ganhadora, na edição, do prêmio honorário entregue pelo Globo de Ouro anualmente, o troféu Cecil B. DeMille. A apresentadora de televisão e atriz norte-americana mobilizou a afetividade por um discurso de luta pela igualdade:

Eu quero todas as garotas assistindo aqui, agora, saibam que um novo dia está no horizonte! E quando esse novo dia finalmente amanhecer, será por causa de muitas mulheres magníficas, muitas das quais estão aqui neste auditório esta noite e alguns homens fenomenais, lutando para garantir que se tornem os líderes que nos levam ao tempo em que ninguém nunca mais terá de dizer "eu também".

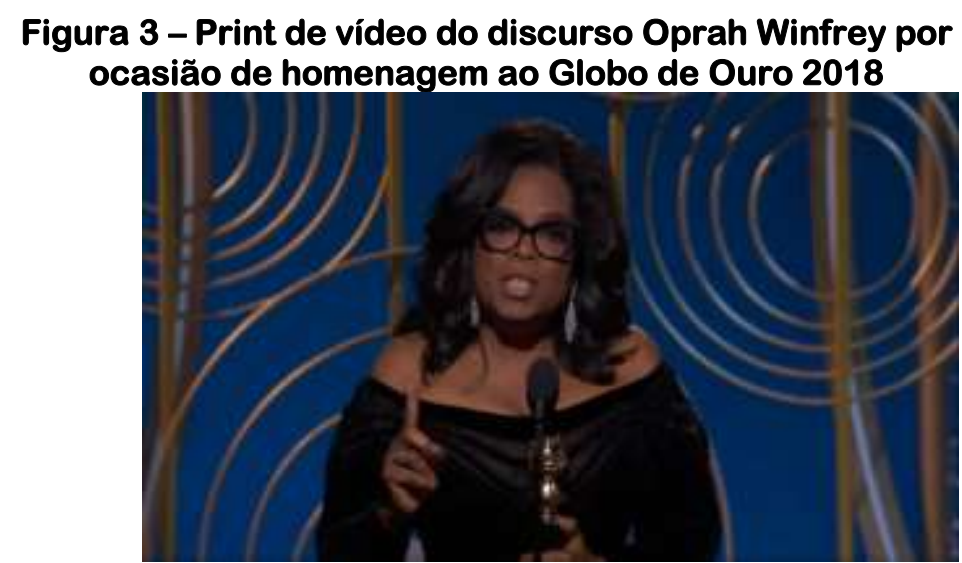

Fonte: Facebook GoldenGlobes. Disponível em: <encurtador.com.br/pxEU6>. Acesso 15 de agosto de 2020.

- Visada de demonstração: caracteriza-se pelo Eu quer "estabelecer a verdade e mostrar as provas" segundo uma certa posição de autoridade de saber; o Tu está em posição de ter que receber e "ter que avaliar" uma verdade e, então, ter a capacidade de fazê-lo (Charaudeau, 2004, p.24).

É o que se identifica no artigo de opinião escrito pela atriz e diretora Amber Tamblyn, publicado no The New York Times $(2018)^{12}$, onde ela contextualiza a escolha do preto para o Globo de Ouro: "O que vestimos não é uma declaração de moda. É uma declaração de ação. É uma mensagem direta de resistência. (...) Esta noite não é de luto. Esta noite é um despertar".

\footnotetext{
${ }^{11}$ Fala da apresentadora Oprah Winfrey. Discurso por ocasião de homenagem ao Globo de Ouro 2018. Los Angeles, 7 jan. 2018.

Disponível em: <https:/www.facebook.com/GoldenGlobes/videos/1884721461569863/>. Acesso 15 de agosto de 2020.

${ }^{12}$ Amber Tamblyn: Redefining the Red Carpet.

Disponível em:<https://www.nytimes.com/2018/01/07/opinion/sunday/amber-tamblyn-golden-globesmetoo.html/>. Acesso em 15 de agosto de 2020.
} 
A partir dessa articulação entre as categorizações das viseés e os discursos de algumas celebridades, nota-se o uso de uma estratégia comunicativa pautada pela lógica da sedução e cuja finalidade seria emocionar e informar, utilizando crenças e valores partilhados pelos receptores para influenciá-los. Conclui-se, pois, que as famosas que estrelaram o tapete vermelho trajando preto lançaram mão das Visadas discursivas para a construção de uma autoimagem, fazendo emergir um ethos enunciador.

\section{A CONSTRUÇÃO DO ETHOS}

Todo discurso pressupõe a construção de uma imagem daqueles que estão envolvidos no ato de comunicação. E, a construção dessa imagem de si no discurso convencionou-se chamar de ethos, $o$ que, para Amossy (2005, p.10), caracteriza-se como "a construção de uma imagem de si destinada a garantir o sucesso do empreendimento oratório".

Porém, vale ressaltar que "a noção tradicional de ethos recobre não somente a dimensão vocal, mas também o conjunto das determinações físicas e psíquicas atribuídas pelas representações coletivas à personagem do orador", como contextualiza Maingueneau (2005, p.72). Essa construção de autoimagem se dá, também, por intermédio das roupas. A corporalidade atribuída a um fiador também acontece através da maneira de se vestir.

A escolha do preto na celebração da $75^{a}$ edição do evento Globo de Ouro propicia a análise sobre a ideação de um possível ethos que seja o fiador das ideologias do grupo do qual se faz parte, visto que, segundo Heine (2009, p.64), "co-enunciadores, baseados em estereótipos estabelecidos socialmente, atribuem aos enunciadores determinadas características e não outras". Dessa forma, pode-se entender que a construção da identidade é tanto simbólica quanto social, e a imagem de si é produto de uma criação discursiva.

O uso da roupa preta como forma de protesto garantiu às famosas atrizes a projeção de um autorretrato que conciliou os ethé de "celebridade engajada" e, ao mesmo tempo, a "bela da noite". Essa enunciação de qualidades garantiu um tapete vermelho cheio de ativistas. Como afirma Barthes (apud MAINGUENEAU, 2011, p.13), ethos "são traços de caráter que o orador deve mostrar ao auditório (pouco importando sua sinceridade) para causar boa impressão".

Além da costumeira pergunta sobre a marca da roupa usada, na edição 75 da premiação ficou em primeiro plano o discurso social e coletivo de resistência e apoio às mulheres que são afetadas por quaisquer situações de exclusão (seja por cor, raça, orientação sexual, deficiências, ocupações profissionais, etc). Outra possível construção imagética, reforçada pelo discurso oral, refere-se ao ethos de sororidade ${ }^{13}$, quando a construção dessa imagem de si se dá por apoio a outras mulheres. É o que afirmou o discurso de Tracee Ellis Ross em sua passagem pelo red carpet: "Eu visto preto hoje como "nós" não como um "eu", como uma celebração de nosso poder coletivo

\footnotetext{
${ }^{13}$ De acordo com Dominique Fougeyrollas-Schwebel (2009, p.146), o termo sororidade (ou sisterhood, no inglês) vincula-se aos movimentos feministas da década de 1970. Segundo a autora, pertencer a tais movimentos representa a realização de uma nova ideologia que recusa toda organização hierárquica.
} 
feminino, como encarnação de irmandade, solidariedade e o trabalho a ser feito para criar mudanças estruturais na sociedade" ${ }^{\text {. }}$.

Resgatando a Retórica de Aristóteles (Maingueneau, 2011), identificam-se duas das qualidades apontadas pelo pensador para a construção de uma imagem positiva de si mesmo. A primeira refere-se a "virtude", uma disposição de caráter relacionada ao agir bem. A segunda refere-se a "benevolência", com seus graus variáveis de piedade e indignação. Estes atributos estão presentes nos discursos não verbais das mulheres que trajaram vestidos pretos como adeptas à causa contra discriminação, assédio e abuso. Projetou-se, nesse cenário, o ethos de mulher ativista, transparecendo uma representação de si mesmas como sendo famosas engajadas em causas sociais e que usam a fama em favor de causas políticas e humanitárias.

As eventuais leituras sobre os ethé projetados pelas atrizes que usaram roupas pretas como forma de protesto no Globo de Ouro não podem ser concebidas como fixas. Como afirma Maingueneau, ethos "é uma noção fundamentalmente híbrida (sociodiscursiva), um comportamento socialmente avaliado, que não pode ser apreendido fora de uma situação de comunicação precisa, integrada ela mesma numa determinada conjuntura sócio-histórica" (MAINGUENEAU, 2011, p.17).

\section{CONSIDERAÇÕES FINAIS}

As celebridades do Globo de Ouro usaram a moda - um dos processos mais antigos de comunicação - como um pacto referencialista dos discursos políticos sociais do movimento Times' up, afirmando seus ideais, suas aspirações e ideologias. $\mathrm{O}$ vestuário, usado como estratégia poderosa e eloquente de discurso, conseguiu mobilizar a atenção para o protesto contra abusos e desigualdades.

Apesar da complexidade do ato de comunicação, considerando os desdobramentos possíveis na relação entre instâncias de produção e recepção, pode-se identificar a aplicabilidade dos conceitos de Contrato Comunicacional - com o reconhecimento ou não do público das representações propostas pelo enunciador - das Visadas Discursivas - e toda intencionalidade do ato de linguagem - e das possíveis construções do ethos do enunciador - por estarem todas vestidas com uma cor que carrega tanto simbolismo.

A tendência, que se iniciou na $75^{\mathrm{a}}$ edição premiação Globo de Ouro, foi mantida durante toda a temporada de prêmios hollywoodianos, como o Grammy e BAFTA, eventos de grande representatividade mundial. Mas, as premiações não foram apenas palco do protesto simbólico de mulheres de preto, mas uma plataforma de projeção da campanha pública norte-americana contra assédio sexual, o Time's up, que, em tradução livre significa "O tempo acabou!".

\footnotetext{
14 Tracee Ellis Ross Celebrates 'Our Collective Power as Women' in All Black at the Golden Globes. Disponível em: <https://people.com/style/golden-globes-2018-tracee-ellis-ross/>. Acesso em 15 de agosto de 2020.
} 


\section{REFERÊNCIAS}

AMOSSY, Ruth (Org.). Imagens de Si no Discurso: a construção do ethos. São Paulo: Contexto, 2008.

BARTHES, Roland. Sistema da Moda. São Paulo: Martins Fontes, 2009.

CHARAUDEAU, P. \& MAINGUENEAU, D. Dicionário de análise do discurso. São Paulo: Contexto, 2004a.

CHARAUDEAU, P. O discurso das mídias. São Paulo: Contexto, 2006

CHARAUDEAU, P. Visadas discursivas, gêneros situacionais e construção textual. In: MACHADO, Ida Lúcia; MELLO, Renato de (Org.). Gêneros: reflexão em Análise do Discurso. Belo Horizonte: NAD/FALE/UFMG, 2004.

COELHO, Maria José de Souza. Moda: um enfoque psicanalítico. Rio de Janeiro: Diadorim, 1995.

Contratos milionários determinam os vestidos do tapete vermelho. Disponível em:<http://www1.folha.uol.com.br/serafina/2017/12/1937324-contratos-milionariosdeterminam-os-vestidos-do-tapete-vermelho.shtml/>. Acesso em 15 de agosto de 2020. ECO, Umberto. O hábito fala pelo monge, in Psicologia do Vestir. 2. ed. Lisboa: Assírio e Alvim, 1982.

FOUGEYROLLAS-SCHWEBEL, Dominique. Movimentos feministas. In: HIRATA, Helena et al. Dicionário crítico do feminismo. São Paulo: Editora UNESP, 2009. p.144149.

Globo de Ouro 2018 | Os mais bem vestidos e os mais mal vestidos da noite. Disponível em:<https://observatoriodocinema.bol.uol.com.br/listas/2018/01/globo-deouro-2018-os-mais-bem-vestidos-e-os-mais-mal-vestidos-da-noite>. Acesso em 15 de maio de 2019.

Globo de Ouro. Disponível em: <encurtador.com.br/iLV46 >. Acesso em 15 de agosto de 2020.

Golden Globes Facebook. Disponível em:<https://www.facebook.com/GoldenGlobes/videos/1884721461569863/>. Acesso em 15 de agosto de 2020.

GUIMARÃES, Luciano. A cor como informação. A construção biofísica, linguística e cultural da simbologia das cores. Ed. Anna Blume. $3^{\text {a }}$ edição, 2004

HEINE, Palmira Virgínia Bahia. Processos de construção do Ethos em blogs de préuniversitários e universitários. Rio de Janeiro: Publit, 2009.

Instagram Times' up. Disponível em:<https://www.instagram.com/timesupnow/>. Acesso em 07/01/2020.

LIBERATOREA, Silvia T. Do simulacro à simbologia cerimonial: um tapete vermelho. Revista F@ro. Universidad de Playa Ancha. Número 1-2, p. 529-542, v. 1-2, 2005. Disponível em:< https://dialnet.unirioja.es/revista/7804/A/2005>.

LIPOVETSKY, Gilles. O império do efêmero: a moda e seu destino nas sociedades modernas. São Paulo: Cia das Letras, 2001.

MAINGUENEAU, Dominique. A propósito do ethos. In: MOTTA, Ana Raquel; SALGADO, Luciana (Org.). Ethos discursivo. 2. ed. São Paulo: Contexto, 2011. 
MAINGUENEAU, D. Ethos, cenografia, incorporação. In AMOSSY, Ruth (Org). Imagens de si no discurso: a construção do ethos. São Paulo: Contexto, 2005.

$O$ red carpet é um negócio milionário para stylists e celebridades. Disponível em: $<$ https://elle.abril.com.br/moda/o-red-carpet-e-um-negocio-milionario-para-stylistse-celebridades/>. Acesso em 15 de maio de 2018.

Oscar 2018: sai o modelito preto, entra a articulação do Time's Up nos bastidores. Disponível em: <https://brasil.elpais.com/brasil/2018/03/02/cultura/ 1520012138_429800.html >. Acesso em 22 de maio de 2018.

ROLIM, Wiliane. V. Estratégias argumentativas no discurso filosófico: estudo de caso à luz da semiolinguística. Dissertação (Mestrado em Estudos Linguísticos) Universidade Federal de Minas Gerais, Belo Horizonte, 2000.

Tracee Ellis Ross Celebrates 'Our Collective Power as Women' in All Black at the Golden Globes. Disponível em: <https://people.com/style/golden-globes-2018-traceeellis-ross/>. Acesso em 15 de agosto de 2020.

Artigo recebido em: ago. de 2020.

Aprovado e revisado em: jan. de 2021.

Publicado em: fev. de 2021.

Para citar este texto:

DRUMOND, Kelly F. Mayrink. Contrato, visada e ethos no tapete vermelho da $75^{a}$ edição do Globo de Ouro. Entremeios [Revista de Estudos do Discurso, ISSN 2179-3514, on-line, www.entremeios.inf.br], Seção Estudos, Programa de Pós-Graduação em Ciências da Linguagem (PPGCL), Universidade do Vale do Sapucaí (UNIVÁS), Pouso Alegre (MG), vol. 23, p. 4-15, Edição especial/ 2020.

DOI: http://dx.doi.org/10.20337/ISSN2179-3514revistaENTREMEIOSvol23pagina4a15 